\title{
Mothers' health service utilization and attitude were the main predictors of incomplete childhood vaccination in east-central Ethiopia: a case-control study
}

Melaku Kindie Yenit ${ }^{1 *}$, Yalemzewod Assefa Gelaw ${ }^{1,2}$ and Atsede Mazengia Shiferaw ${ }^{3}$

\begin{abstract}
Background: Vaccination is an effective public health intervention for reducing childhood morbidity and mortality. It becomes more effective if the child receives the full course of the recommended doses. In Ethiopia, many children fail to complete the full course, and there is a consensus on the low coverage of complete vaccination; however, factors relating to the problem have not been largely explored by community based studies. The problem still persists posing a challenge to the health care delivery system. Therefore, this study assessed the predictors of incomplete childhood vaccination among children aged 12-23 months. The result is expected to improve health promotion efforts to boost childhood vaccination uptake and serve as a tool for increasing the utilization of the existing Expanded Program on Immunization efforts.
\end{abstract}

Methods: A community-based unmatched case-control study was conducted in six kebeles of Amanuel district in east-central Ethiopia from March to April 2014. Census was carried out to identify cases and controls. A total of 308 mother-child pairs (154 cases and 154 controls) were selected by the stratified multistage sampling technique. Cases were children in the 12-23 months age group who missed at least one dose of the recommended vaccination. Child vaccination cards and mothers' oral responses were used to verify the vaccination status of each child. Data were collected using interviews through a pretested structured questionnaire and analyzed using SPSS version 20. A p-value of less than 0.05 was considered for declaring statistical significance.

Results: The study revealed that the odds of defaulters from childhood vaccinations noted among mothers who delivered at home were high $[A O R=4.11,(95 \% \mathrm{Cl}: 2.26,7.47)]$. Other irregularities detected were lack of antenatal care visits during pregnancy $[\mathrm{AOR}=2.54,(95 \% \mathrm{Cl}: 1.31,4.95)]$, misperception about vaccines [AOR: $2.83,95 \% \mathrm{Cl}$ : $(1.56,5.15)]$, and lack of postnatal care visits $[\mathrm{AOR}=2.51,95 \% \mathrm{Cl}:(1.18,5.33)]$.

Conclusion: Home deliveries, a misconception on vaccine, lack of prenatal and postnatal care services were found to be the predictors of incomplete childhood vaccinations. Therefore, increasing mothers' awareness on childhood vaccination, strengthening maternal health service utilization, and supervision and monitoring are highly recommended to reduce incomplete vaccination in the study setting.

Keywords: Predictors, Incomplete vaccination, 12-23 months children, Case-control study: East-central Ethiopia

\footnotetext{
* Correspondence: melaku98@gmail.com

${ }^{1}$ Department of Epidemiology and Biostatistics, Institute of Public Health,

University of Gondar, Gondar, Ethiopia

Full list of author information is available at the end of the article
} 


\section{Background}

Immunization remains one of the most cost-effective public health interventions to reduce childhood morbidity and mortality $[1,2]$. Since it is accessible to the most hard-to-reach and vulnerable population, it is considered as a globally proven strategy for childhood intervention. Each year, immunization averts more than 2 million vaccine-preventable deaths globally [3-6]. Vaccination becomes more effective when it is administered with the most potent vaccine at the appropriate age $[7,8]$. In connection to this, the World Health Organization (WHO) recommends that it should be made sure that all children receive all necessary doses of all vaccines before their first birthday. Thus, children are considered as fully vaccinated when they have received vaccinations against tuberculosis (BCG), three doses of pentavalent vaccine DPT-Hep-Hib, polio vaccines, two dose of Rota, pneumonia and a measles $[9,10]$.

Although vaccination offers greater benefits of health, well-being, and survival of children than any other interventions, vaccine-preventable diseases are still responsible for about $25 \%$ of deaths of under-five children [3, 11]. Most of the deaths are from diarrheal diseases, acute respiratory infections, and measles. Globally, about 22.6 million children under the age of 1 year are partially protected, and more than a quarter of these are reported in low and middle-income countries $[3,12,13]$.

In spite of the accepted benefits of vaccination for childhood survival and health, full childhood vaccination practice has been diverse and affected by various factors, such as wealth status [11, 14-16], mothers' age [11, 14, 15, 17-19], mothers' education [11, 14, 15, 19-23], history of prenatal care [14, 17, 24], child sex and age [11], birth place $[17,21,24,25]$, residence $[11,26]$, mothers' knowledge about immunization [14, 16, 23, 24, 27, 28], health workers' home visits [17], missing opportunities [29], distance to health institutions $[14,21,26]$ and perception about the benefits of immunization [11, 19, 26, 27].

In Ethiopia, a routine immunization program was launched by providing six traditional antigens in 1980 . The Program was revised subsequently and was capable of providing 10 vaccines to under 1 year of age at the moment $[30,31]$. In addition to the traditional vaccines that are given without any charge, new vaccines are continuously introduced into the Immunization Program. Recently, the program has successfully introduced additional antigens which have resulted in the protection of millions of children from vaccine-preventable diseases. Haemophilus influenza type B and Hepatitis B vaccines were introduced in the form of a pentavalent combination vaccine in 2007, while Pneumococcal Conjugate (PCV-10) and Rotavirus vaccines were introduced in 2011 and 2013, respectively [6, 32, 33]. Currently, vaccination in Ethiopia is being given on routine and outreach bases. Thus the national routine vaccination schedule recommends that childhood vaccination should start from birth and be completed before the first birthday with one dose of bacillus Calmette-Guerin (BCG), oral polio vaccine doze (OPV 0), three doses of OPV, Pentavalent, two doses of Rota, pneumonia vaccines, and finally measles vaccine at the age of 9 months. Moreover, Inactivated Polio Virus (IPV), measles-rubella, meningitis, and yellow fever vaccines for less than one-year-old children are planned under the implementation [32, 33] (Table 1).

Currently, immunization services are given to 3 million children under the age of 1 year in most health facilities. Despite various government initiatives, incomplete vaccination has still been a problem in the country. In Ethiopia, vaccination coverage among children aged 12-23 months is the highest $(81 \%)$ for the first dose of polio vaccine, followed by $73 \%$ of first dose of DPT-HepB-Hib vaccine. The 2016 Ethiopian Demographic and Health Survey (EDHS) indicated that more than half $(53 \%)$ of children in Ethiopia received three doses of the DPT-HepB-Hib vaccine and 54\% measles vaccination [9]. Nationally, the dropout rate from the first to the third dose of (DPTHepB-Hib and polio vaccine) was $20 \%$ and $25 \%$, respectively [9]. According to the national report of EDHS in 2016, there was a steady progress in full immunization coverage, and the percentage of children aged 1223 months who received all basic vaccinations increased from $14 \%$ in 2000 to $20 \%$ in 2005 [34], from $24 \%$ in 2011 [35] to $39 \%$ in 2016 [9]. However, the national full vaccination coverage in 2016 increased by $25 \%$ from the level reported in the 2000 EDHS. This remained far below the goal of $66 \%$ coverage set in HSDP IV and the $90 \%$ target in 2020 [36]. Particularly, the Amhara Region had a low level of full immunization of $26.3 \%$ in 2011 and $46 \%$ in 2016, and the district in question is known for frequent outbreaks of vaccine-preventable diseases, especially measles. Full vaccination coverage in Ethiopia varied by region, and the lowest full vaccination coverage of $15 \%$ was

Table 1 Routine immunization schedule in Ethiopia, 2014

\begin{tabular}{|c|c|c|c|}
\hline Vaccines & $\begin{array}{l}\text { Number } \\
\text { of dose }\end{array}$ & Disease prevent & $\begin{array}{l}\text { Age at which } \\
\text { vaccine delivered }\end{array}$ \\
\hline$\overline{B C G}$ & One dose & Tuberculosis & At birth \\
\hline Pentavalent & 3 (Penta 1,2 \& 3) & $\begin{array}{l}\text { Diphtheria, Pertussis, } \\
\text { Tetanus, H. influenza } \\
\text { type b, Hepatitis B }\end{array}$ & $6,10,14$ weeks \\
\hline OPV & 3 doses & Polio & $\begin{array}{l}\text { At birth, } 6,10, \\
14 \text { weeks }\end{array}$ \\
\hline $\begin{array}{l}\text { Pneumonia- } \\
\text { conjugate } \\
\text { vaccine (PCV) }\end{array}$ & 3 doses & Pneumonia & $6,10,14$ weeks \\
\hline Rota & 2 dose & Rota Virus & 6,10 weeks \\
\hline Measles & one dose & Measles & 9 months \\
\hline
\end{tabular}

${ }^{\mathrm{OPV}}$ Oral polio vaccine, ${ }^{\mathrm{BCG}}$ Baccille Calmette-Guerin 
reported in Afar Region. Although there has been progress in full vaccination coverage, many children in the country do not get the full benefits of the program [10], and full immunization coverage is less than the herd immunity level desired to prevent the spread of vaccine-preventable diseases.

Most of the studies conducted earlier on immunization were part of the coverage evaluation surveys (cross-sectional), so there were chances of recall bias. Therefore, this study can minimize this research gap and draw attention to the largely unexplored factors that may be associated with incomplete childhood immunization. The study thus assessed factors associated with incomplete vaccinations among children 12-23 months of age at Amanuel district to generate data that could be used for better planning and strengthening routine immunization services.

\section{Methods}

\section{Study design and setting}

A community-based unmatched case-control study was conducted from March to April 2014 in Amanuel, one of the 18 districts in East Gojam Zone, Amhara Regional State, east-central Ethiopia. The district is known for frequent outbreaks of vaccine-preventable diseases, especially measles. It has 26 kebeles (one urban and 25 rural), and an estimated total population of 133,188. Initially, the kebeles (the smallest administrative units in Ethiopia) in the district were stratified into urban and rural settlements.

\section{Sample size and sampling procedure}

Mothers who had children aged 12-23 months were the population under study. Sample size was calculated using Epi-info version 3.5.3 by considering the following assumptions, proportion of illiterate mothers or caretakers among controls 52\%, among cases 76\% [37], 95\% level of confidence, $5 \%$ margin of error, a design effect of 2, case: control ratio of $1: 1$, and $15 \%$ non -response rate. Finally, the minimum sample size of 308 (154 cases and 154 controls) was obtained. Initially, the district was stratified into urban and rural kebeles. Out of the total 25 rural kebeles, 6 were selected randomly, and the only urban kebele was included. Mother-child pairs were recruited from six rural and one urban kebeles. A community survey was conducted a week before the actual data collection to identify cases and controls (Tables 2 and 3). The final sample size of cases and controls from each kebele was allocated based on the probability proportional size to the number of children aged 12-23 months. As a result, participants were mothers who had children aged 12-23 months in the kebels selected by the stratified multistage random sampling method and were assigned based on proportion to size to each kebele (Fig. 1).
Table 2 Number of case and control identified during survey stratified by study kebeles in Amanuel District, east-central Ethiopia, 2014

\begin{tabular}{lll}
\hline & \multicolumn{2}{l}{ Study populations from survey } \\
\cline { 2 - 3 } Study Kebele & Cases & Controls \\
\hline Yewulla & 29 & 65 \\
Delma & 24 & 78 \\
Degasegnen & 33 & 56 \\
Amanuel 01 & 41 & 110 \\
Zuria & 38 & 49 \\
Yedefas & 26 & 42 \\
Kerer & 19 & 53 \\
Total & 210 & 453 \\
\hline
\end{tabular}

\section{Data collection tools and procedures}

A structured interviewer-administered questionnaire was used to collect the data. In addition to WHO EPI data collection forms, instruments were constructed by reviewing a variety of literature. The instrument consisted of socio-demographic and economic variables, mother health service related characteristics, and knowledge and attitude on immunization. Moreover, health care access and satisfaction with health care service were assessed in the questionnaire. To maintain consistency, the questionnaire was first translated from English to Amharic (the native language of the study area) and was retranslated to English by professional translators and public health experts. Five clinical nurses and two health officers were recruited as data collectors and supervisors, respectively. A two-day intensive training regarding the objective of the study, confidentiality of information, and techniques of conducting interviews was given to both groups. The tool was also piloted on $5 \%$ of the total sample out of the study area, and the acceptability and applicability of the procedures and tools were evaluated by the pretest.

Table 3 Proportional allocation of case and control in each kebeles in Amanuel district, east-central Ethiopia, 2014

\begin{tabular}{lll}
\hline & \multicolumn{2}{l}{ Sample populations } \\
\cline { 2 - 3 } Kebele & Cases & Controls \\
\hline Yewulla & 21 & 22 \\
Delma & 18 & 27 \\
Degasegnen & 24 & 19 \\
Amanuel 01 & 30 & 37 \\
Zuria & 28 & 17 \\
Yedefas & 19 & 14 \\
Kerer & 14 & 18 \\
Total & 154 & 154 \\
\hline
\end{tabular}




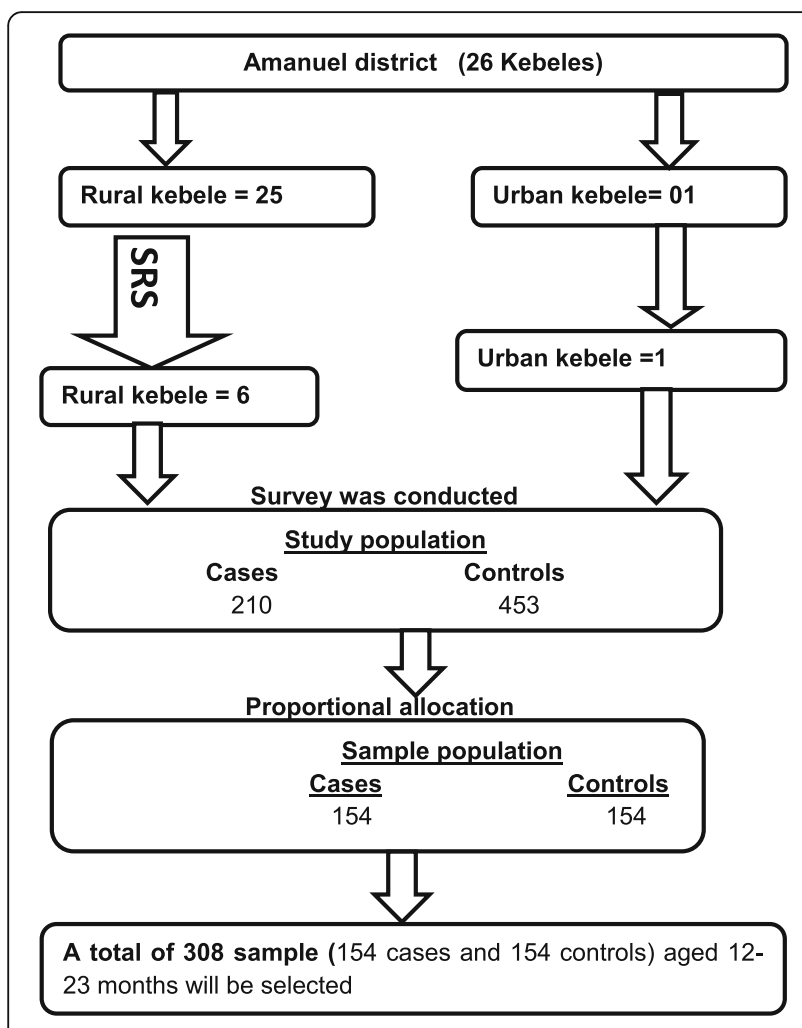

Fig. 1 Sampling procedure of study kebeles in Amanuel district beast-central Ethiopia, 2014

\section{Operational definitions and study variables}

- Complete vaccination: A child aged 12-23 months and took all the recommended vaccines, that is, a dose of Baccille Calmette-Guerin (BCG), three doses of Pentavalent and PCV, three doses of OPV, and a measles vaccine before their first birthday (by the age of 12 months). The child vaccination card and mother's oral response were used to verify vaccination status of the child.

- Incomplete vaccination: Children in the age group of 12-23 months who missed at least one of the recommended vaccines before their first birthday (by the age of 12 months).

- Cases and controls: A case was defined as a child between 12 and 23 months old who missed at least one dose of the nine vaccines before their 1st birthday, while controls were defined as children who took all the recommended vaccines.

- Knowledge of schedules of immunization: Mothers' knowledge of the schedules of vaccination was assessed using nine questions. Mothers were asked about the age at which the children began immunization, at what age measles vaccine was administered, about the number of vaccinations needed for a child to be fully immunized, and the age at which children completed the immunizations. The composite knowledge index was analyzed using the Principal Component Analysis and converted into tercile as "poor", "medium", and "good".

- Household wealth index: The household wealth index was computed using a composite indicator for urban and rural residents by considering household asset properties and size of agricultural land. Principal Component Analysis was performed to categorize the household wealth index into "lowest", "middle", and "highest".

- Health care access: Mothers' health care access was determined by asking them how many hours it took them to reach health care facilities. If it took less than two hours, it was considered as "good" health care access and was coded as "1"; otherwise, "0" if it took two hours or more.

- Missed opportunity: It was assessed if a child came to a health facility or an outreach site and did not receive the vaccination for which they were eligible.

- Misconceptions about vaccine contraindication:

This was measured by asking misconception related questions using a five-option likert scale ranging from "strongly agree" to "strongly disagree". After computing the mean score, the status was dichotomized into "positive" and "negative" misconception about vaccine contraindication.

\section{Data processing and analysis}

Data were entered into Epi-info version 3.5.3 and exported to the Statistical Package for Social Sciences (SPSS) version 20 for further analysis. Data cleaning was performed by running frequencies. Descriptive statistics, including frequencies and proportions were computed to summarize the variables by using the binary logistic regression model. Both bivariate and multivariate logistic regression analyses were entered into the multivariate analysis. Variables with a $p$-value of $\leq 0.2$ in the bivariate analysis were entered into the multivariate analysis. Both Crude Odds Ratio (COR) and the Adjusted Odds Ratio (AOR) with a 95\% confidence interval were estimated to show the strength of associations. A $p$-value of $\leq 0.05$ was used to identify variables that showed statistical significance in the multivariate analysis.

\section{Results}

Socio-demographic and economic characteristics

A total of 302 mother-infant pairs (152 controls and 150 cases) were included in the study. The mean $( \pm$ SD) age of the mothers and the children was $29.53( \pm 5.10)$ years and $16.92( \pm 3.17)$ months, respectively. In this study, more than three-fourths of cases and controls $(79.9 \%$ and $76.3 \%$, respectively) were rural dwellers. Two-thirds (64\%) of cases and more than one-third (39.1\%) of controls were male. Most of the caretakers for the controls 
and the cases (99.3\% and 93.3\%, respectively) were mothers. About two-thirds of the cases and the controls $(70 \%$ and $63.8 \%)$ were uneducated. More than half of the cases and the controls of the mothers (68.5\% and $58.3 \%$, respectively) gave birth in less than 2 years of interval. The mean $( \pm S D)$ next childbirth interval for cases and controls was 18 $( \pm 9.1)$ and $21( \pm 11.4)$ months, respectively. Threefourths of the cases (74.5\%) and nearly half of the controls (47\%) gave birth more than three times. About two-thirds of the cases (63.3\%) were born in the second order of birth, while $63.8 \%$ of the controls were born in the third order. More than three-fourths (75.3\%) of cases and less than half of $(48.7 \%)$ the controls' mothers had more than five family members (higher than the national average) (Table 4).

\section{Mothers' health service related characteristics}

It was revealed that most (95.3\% and $98.7 \%$, respectively) of the cases and the controls had heard about immunization. About $61.2 \%$ of the cases did not get health worker home visits in the last 1 month, while more than two-thirds of the controls (69.7\%) were visited by community health workers. One-third of cases (34.7\%) and more than twothirds of controls (73\%) attended their prenatal care visits during their pregnancy. The report indicated that only onethird (35.3\%) of cases preferred to deliver at health institutions. About one-third of the controls and the cases $(31.3 \%$ and $36.2 \%$, respectively) had poor access to health care (more than $2 \mathrm{~h}$ ) (Table 5).

More than half $(56.7 \%)$ of the cases did not maintain their vaccination cards, while about $57.6 \%$ of the controls' vaccination cards were maintained by the mothers or caretakers. Level of satisfaction with the health care provision indicated that two-thirds of the cases (67.3\%) and one-third of the controls (39.5\%) were not satisfied. A significant portion of the cases $(66.7 \%)$ had a misconception on vaccine, while a similar proportion of the controls $(67.8 \%)$ had favorable attitude towards vaccination. A similar proportion of the cases and controls (65.3\% and $64.5 \%$, respectively), had a positive perception of the benefits of vaccines (Table 5).

\section{Predictors of incomplete childhood vaccination}

Both bivariate and multivariate analyses were done to identify the predictors of incomplete childhood vaccination. The result of the bivariate analysis showed that the age of mothers and children, health worker home visits, lack of prenatal and postnatal care, home delivery, the level of mother's satisfaction, knowledge of vaccination, misconception about vaccines, and missed opportunity were common predictors of incomplete vaccination with a $p$-value of 0.2 .

Consequently, these variables were subjected to multivariate analysis, and it was noted that higher odds of
Table 4 Socio-demographic and economic characteristics of respondents in Amanuel district, east-central Ethiopia, 2014

\begin{tabular}{|c|c|c|}
\hline \multirow[t]{2}{*}{ Variables } & \multicolumn{2}{|c|}{ Incomplete childhood vaccination } \\
\hline & $\begin{array}{l}\text { Yes } \\
N(\%)\end{array}$ & $\begin{array}{l}\text { No } \\
N(\%)\end{array}$ \\
\hline \multicolumn{3}{|l|}{ Residency } \\
\hline Urban & $30(20.1 \%)$ & $36(23.7 \%)$ \\
\hline Rural & 119 (79.9\%) & $116(76.3 \%)$ \\
\hline \multicolumn{3}{|l|}{ Child's caretaker } \\
\hline Mother & $140(93.3 \%)$ & $151(99.3 \%)$ \\
\hline Grandparent & $10(6.7 \%)$ & $1(.7 \%)$ \\
\hline \multicolumn{3}{|l|}{ Marital status } \\
\hline Married & 137 (91.3\%) & $151(99.3 \%)$ \\
\hline Divorced/separated & $9(6.0 \%)$ & $1(0.7 \%)$ \\
\hline Widowed & $2(1.3 \%)$ & $0(.0 \%)$ \\
\hline \multicolumn{3}{|l|}{ Caretakers' age (years) } \\
\hline$<26$ & $29(19.7 \%)$ & $48(31.6 \%)$ \\
\hline $27-34$ & $88(59.9 \%)$ & $98(64.5 \%)$ \\
\hline$>35$ & $30(20.4 \%)$ & $6(3.9 \%)$ \\
\hline \multicolumn{3}{|l|}{ Educational status } \\
\hline No education & 105 (70.0\%) & $97(63.8 \%)$ \\
\hline Primary [1-8] & $20(13.3 \%)$ & $32(21.1 \%)$ \\
\hline Secondary [9-12] & $10(6.7 \%)$ & $6(3.9 \%)$ \\
\hline College and above & $15(10.0 \%)$ & $17(11.2 \%)$ \\
\hline \multicolumn{3}{|l|}{ Child sex } \\
\hline Male & $96(64.0 \%)$ & $59(39.1 \%)$ \\
\hline Female & $54(36.0 \%)$ & $92(60.9 \%)$ \\
\hline \multicolumn{3}{|l|}{ Child age (months) } \\
\hline $12-18$ & $78(52.0 \%)$ & $105(69.1 \%)$ \\
\hline $19-23$ & $72(48.0 \%)$ & $47(30.9 \%)$ \\
\hline \multicolumn{3}{|l|}{ Parity } \\
\hline One & $10(6.7 \%)$ & $27(17.9 \%)$ \\
\hline Two & $28(18.8 \%)$ & $53(35.1 \%)$ \\
\hline More than three & $111(74.5 \%)$ & $71(47.0 \%)$ \\
\hline \multicolumn{3}{|l|}{ Birth order } \\
\hline 1 & $19(12.7 \%)$ & $36(23.7 \%)$ \\
\hline $2-3$ & 95 (63.3\%) & 97 (63.8\%) \\
\hline$\geq 4$ & $36(24.0 \%)$ & $19(12.5 \%)$ \\
\hline \multicolumn{3}{|l|}{ Birth interval (in month) } \\
\hline $4-36$ & $39(26.2 \%)$ & $58(38.4 \%)$ \\
\hline$\geq 37$ & $8(5.4 \%)$ & $5(3.3 \%)$ \\
\hline \multicolumn{3}{|l|}{ Family size } \\
\hline$\leq 3$ & $37(24.7 \%)$ & $78(51.3 \%)$ \\
\hline$\geq 4$ & $113(75.3 \%)$ & $74(48.7 \%)$ \\
\hline \multicolumn{3}{|l|}{ Wealth index } \\
\hline Poor & $51(34.0 \%)$ & $51(33.6 \%)$ \\
\hline Medium & $36(24.0 \%)$ & $33(21.7 \%)$ \\
\hline Rich & $63(42.0 \%)$ & $68(44.7 \%)$ \\
\hline
\end{tabular}


Table 5 Mother health service related characteristics of respondents in Amanuel district, east-central Ethiopia, 2014

\begin{tabular}{lll}
\hline Variables & \multicolumn{3}{l|}{ Incomplete childhood vaccination } \\
\cline { 2 - 3 } & Yes & No \\
$N(\%)$ & $N(\%)$
\end{tabular}

Hear about vaccination

Yes

No

Health workers' home visit

Yes

No

Antenatal care visit (ANC)

No

$\leq 2$

$\geq 3$

Post natal care visit (PNC)

Yes

No

TT Vaccination

Yes

No

Health care access

Within $2 \mathrm{~h}$

$>2 \mathrm{~h}$

Place of delivery

Home

Health Institution

Vaccination card available

Yes

$143(95.3 \%)$

$7(4.7 \%)$

\section{7 (38.8\%)}

$90(61.2 \%)$

$98(65.3 \%)$

$34(64.0 \%)$

$18(36.0 \%)$

$20(13.3 \%)$

$130(86.7 \%)$

$47(31.3 \%)$

$103(68.7 \%)$

$100(66.7 \%)$

47 (31.3\%)

97 (64.7\%)

$53(35.3 \%)$

$65(43.3 \%)$

No

85 (56.7\%)

Level of satisfaction

Satisfied

$101(67.3 \%)$

Not satisfied

Missed opportunity

Yes

No

$90(61.6 \%)$

$56(38.4 \%)$

Knowledge on the schedule of vaccination

$\begin{array}{lll}\text { Poor } & 46(30.7 \%) & 37(24.3 \%) \\ \text { Medium } & 39(26 \%) & 55(36.2 \%) \\ \text { Good } & 65(43.3 \%) & 60(39.5 \%)\end{array}$

Good

$65(43.3 \%)$

Misconception on vaccine contraindication

$$
\begin{array}{ll}
\text { Yes } & 100(66.7 \%) \\
\text { No } & 50(33.3 \%)
\end{array}
$$

$49(32.2 \%)$

$103(67.8 \%)$

Perception on benefit of vaccine

$\begin{array}{lll}\text { Positive } & 98(65.3 \%) & 98(64.5 \%) \\ \text { Negative } & 52(34.7 \%) & 54(35.5 \%)\end{array}$

defaulting from childhood vaccinations were noted among children delivered at home $[\mathrm{AOR}=4.11,95 \% \mathrm{CI}: 2.26$, 7.47], mothers who had no prenatal [AOR $=2.54,95 \%$ CI: $1.31,4.95]$, and postnatal care $[\mathrm{AOR}=2.51,95 \%$ CI: 1.18, 5.33], mothers of higher parity $(\geq 3)[\mathrm{AOR}=$ 3.55, 95\% CI: 1.32, 9.58], and mothers who had misconception about vaccination $[\mathrm{AOR}=2.83,95 \% \mathrm{CI}$ : 1.56, 5.15] (Table 6).

\section{Discussion}

The study assessed the predictors of incomplete vaccination among children aged 12-23 months in Amanuel district, East Gojjam zone. Socio-demographic and mothers' health service utilization characteristics were assessed, and the adjusted logistic regression analysis indicated that antenatal and post-natal care services, place of delivery, parity, and misconceptions on vaccine were the predictors of incomplete childhood vaccination.

Immunization is one of the most powerful and costeffective health interventions globally. It prevents debilitating illnesses and disability and saves millions of lives every year. Vaccines have the power not only of saving but also of transforming lives, giving children the chance to grow up healthy, go to school, and improve their life prospects [38]. Considering this acknowledged benefits of immunization, Ethiopia has adapted these established facts and set a target to improve full vaccination to reach $90 \%$ by 2020 [36].

In this study, the result of the adjusted analysis indicated that the odds of defaulters from child vaccination were higher among mothers who had no prenatal care service during pregnancy than mothers who had prenatal care visits. The finding was supported by reports elsewhere $[14,17,24]$. Similarly, mothers who had no postnatal care visits had high odds of defaulting from childhood vaccination compared to mothers who had postnatal care visits. This may be due to the fact that mothers who had no prenatal and postnatal care visits missed the chance of communicating with health care providers to hear about the benefits of vaccination and the relevance of completing it. The impact of prenatal and postnatal care information mainly operates through the role of clinicians in the process of providing the right and up-to-date information to mothers. In fact, birth preparedness and immunization counseling are important components of prenatal care, and repeated visits help to bring the intended maternal behavioral change toward full childhood vaccination.

Similarly, in this study, higher odds of defaulters from childhood vaccination were reported among mothers who delivered at home. The finding of the study was in line those with other studies conducted in Ethiopia [24, 39, 40], Mozambique [21], Kenya [25], and Tokyo [17]. This could be so due to the fact that home delivery was considered as a proxy determinant of poor access to health care service utilization. In addition, mothers who give birth at health 
Table 6 Multivariable logistic regressions analysis for predictors of incomplete childhood vaccination in Amanuel District, east-central Ethiopia, 2014

\begin{tabular}{|c|c|c|c|c|}
\hline \multirow[t]{2}{*}{ Variables } & \multicolumn{2}{|c|}{ Incomplete childhood vaccination } & \multirow{2}{*}{$\begin{array}{l}\text { Crude OR } \\
(95 \% \text { Cl) }\end{array}$} & \multirow{2}{*}{$\begin{array}{l}\text { Adjusted OR } \\
(95 \% \mathrm{Cl})\end{array}$} \\
\hline & Yes (\%) & No (\%) & & \\
\hline \multicolumn{5}{|c|}{ Mothers' age (in years) } \\
\hline$\leq 26$ & $29(19.7 \%)$ & $48(31.6 \%)$ & $0.67(0.39,1.16)$ & $0.77(0.38,1.57)$ \\
\hline $27-34$ & $88(59.9 \%)$ & $98(64.5 \%)$ & 1.00 & 1.00 \\
\hline$\geq 35$ & $30(20.4 \%)$ & $6(3.9 \%)$ & $5.57(2.21,14.01)$ & $2.62(0.87,7.94)$ \\
\hline \multicolumn{5}{|c|}{ Health worker home visit } \\
\hline Yes & $57(38.8 \%)$ & $106(69.7 \%)$ & 1.00 & 1.00 \\
\hline No & $90(61.2 \%)$ & $46(30.3 \%)$ & $3.64(2.25,5.87)$ & $1.09(0.53,2.27)$ \\
\hline \multicolumn{5}{|l|}{ ANC } \\
\hline Yes & $52(34.7 \%)$ & $111(73.0 \%)$ & 1.00 & 1.00 \\
\hline No & $98(65.3 \%)$ & $41(27.0 \%)$ & $5.10(3.12,8.34)$ & $2.54(1.31,4.95) *$ \\
\hline \multicolumn{5}{|l|}{ PNC } \\
\hline Yes & $20(13.3 \%)$ & $51(33.6 \%)$ & 1.00 & 1.00 \\
\hline No & $130(86.7 \%)$ & $101(66.4 \%)$ & $4.60(2.60,8.14)$ & $2.51(1.18,5.33) *$ \\
\hline \multicolumn{5}{|l|}{ Tा vaccination } \\
\hline Yes & $47(31.3 \%)$ & $76(50.0 \%)$ & 1.00 & 1.00 \\
\hline No & $103(68.7 \%)$ & $76(50.0 \%)$ & $2.19(1.37,3.50)$ & $1.55(0.27,1.11)$ \\
\hline \multicolumn{5}{|l|}{ Place of delivery } \\
\hline Home & $97(64.7 \%)$ & $32(21.2 \%)$ & $6.81(4.07,11.38)$ & $4.11(2.26,7.47) *$ \\
\hline Health institution & $53(35.3 \%)$ & 119 (78.8\%) & 1.00 & 1.00 \\
\hline \multicolumn{5}{|l|}{ Parity } \\
\hline One & $10(6.7 \%)$ & 27 (17.9\%) & 1.00 & 1.00 \\
\hline Two & $28(18.8 \%)$ & $53(35.1 \%)$ & $1.42(0.61,3.36)$ & $1.48(0.49,4.41)$ \\
\hline Above three & $111(74.5 \%)$ & $71(47.0 \%)$ & $4.22(1.93,9.23)$ & $3.55(1.32,9.58) *$ \\
\hline \multicolumn{5}{|c|}{ Child age (in months) } \\
\hline $12-18$ & $78(52.0 \%)$ & $105(69.1 \%)$ & $0.48(0.30,0.77)$ & $0.52(0.28,1.95)$ \\
\hline \multicolumn{5}{|l|}{$\begin{array}{c}19-23 \\
\text { Birth order }\end{array}$} \\
\hline First & $19(12.7 \%)$ & $36(23.7 \%)$ & $0.27(0.13,0.61)$ & $0.78(0.33,1.81)$ \\
\hline Second \& third & 95 (63.3\%) & $97(63.8 \%)$ & $0.52(0.28,0.97)$ & $1.42(0.41,4.87)$ \\
\hline Above four & $36(24.0 \%)$ & $19(12.5 \%)$ & 1.00 & 1.00 \\
\hline \multicolumn{5}{|c|}{ Knowledge on vaccine schedule } \\
\hline Poor & $46(30.7 \%)$ & $37(24.3 \%)$ & $1.72(1.23,4.37)$ & $1.24(0.57,5.63)$ \\
\hline Medium & $39(26 \%)$ & $55(36.2 \%)$ & $1.63(1.027,2.580)$ & $1.17(0.64,2.18)$ \\
\hline Good & $65(43.3 \%)$ & $60(39.5 \%)$ & 1.00 & 1.00 \\
\hline \multicolumn{5}{|l|}{ Level of satisfaction } \\
\hline Satisfied & 49 (32.7\%) & $92(60.5 \%)$ & 1.00 & 1.00 \\
\hline Dissatisfied & $101(67.3 \%)$ & $60(39.5 \%)$ & $3.16(1.97,5.06)$ & $2.94(0.45,1.93)$ \\
\hline \multicolumn{5}{|c|}{ Misconception on vaccine } \\
\hline Yes & $100(66.7 \%)$ & $49(32.2 \%)$ & $4.20(2.600,6.798)$ & $2.83(1.56,5.15)^{*}$ \\
\hline No & $50(33.3 \%)$ & $103(67.8 \%)$ & 1.00 & 1.00 \\
\hline \multicolumn{5}{|l|}{ Missed opportunity } \\
\hline Yes & $90(61.6 \%)$ & $56(37.1 \%)$ & $2.73(1.705,4.360)$ & $1.23(.637,2.386)$ \\
\hline No & 56 (38.4\%) & 95 (62.9\%) & 1.00 & 1.00 \\
\hline
\end{tabular}

*Significant at a $p$-value of $<0.05$ 
facilities are closer to health services, and most of the time the first doses of vaccination are given just after birth in health institutions. The other probable justification can be explained by the fact that home delivery can be an indicator for the absence of health extension worker home visit (the case of Ethiopia) which subsequently affects health care service utilization.

In the study, it was noted that mothers who had more than three parities had higher odds of defaulting from childhood vaccination compared to those who had only one. The finding is consistent with reports from Kenya and Bangladesh [14, 25]. This can be due to the fact that having more children may have a negative effect on health care utilization owing to competing for care responsibilities and because more children place competing demands on mothers, while time and resources available for the care of each child become less available.

The study also noted that mothers' misconception about vaccines is a predictor for incomplete childhood vaccination. This finding is similar to that of a study conducted elsewhere $[11,19,26,28,41]$. This is due to the fact that if mothers have a negative perception on the use of vaccination and its possible side effects, they will be less likely to take their children for vaccination according to schedule.

Though the study did its best to indicate the predictors of incomplete childhood vaccination, it is not free from limitations. Firstly, the measurement of vaccination status was based on vaccination cards and mothers' recall. Secondly recall bias in the reporting of vaccination status was not ruled out. Finally, variables that needed further qualitative investigations were not included.

\section{Conclusion}

In this study, incomplete vaccinations were noted among older children and mothers who lacked prenatal and postnatal care services, delivered at home, had multiple parity and misconceptions about vaccine contraindications. Therefore, the District Health Office needs to focus on strategies that could increase mothers' awareness of vaccination; health care providers should motivate and counsel mothers to attend antenatal and postnatal care health services. In addition, strategies such as health worker home visits could be used to identify defaulters in the district and work to help pregnant women to attend ANC, to deliver at health institution, and access PNC services. In addition, supervision and monitoring should be strengthened to increase full immunization coverage. Reminding and tracing mechanism is required for parents who default from childhood vaccination. Moreover, professional work on arousing health-seeking behavior, providing health education and communication are essential for curbing the poor and incomplete childhood immunization practice in the study community.

\section{Abbreviations}

ANC: Antenatal care; AOR: Adjusted odds ratio; BCG: Baccille calmette guerin; Cl: Confidence interval; COR: Crude Odds ratio; DPT: Diphtheria Pertussis and Tetanus; OPV: Oral polio vaccine; PCA: Principal component analysis; SPSS: Statistical Package For Social Sciences and; WHO: World Health Organization

\section{Acknowledgements}

We are indebted to study participants, data collectors, and supervisors for their commitment of taking part in the study.

\section{Funding}

No fund was obtained for this study.

\section{Availability of data and materials}

Data will be available upon request from the correspondence authors.

\section{Authors' contributions}

MKY conceived of the study, design of the study and tool development coordinated data collection, performed statistical analysis, and drafted the manuscript. YAG and AMS performed statistical analysis and drafted the manuscript. All authors read and approved the final manuscript.

\section{Ethics approval and consent to participate}

Ethical clearance was obtained from the Ethical Review Board of Jimma University, and a letter of permission from the Zonal Health Department prior to data collection. After the objective of the study was explained, verbal consent was secured from mothers. The right of participants to withdraw from the study at any time without any precondition was communicated unequivocally. Moreover, the confidentiality of information gathered was guaranteed by all data collectors and investigators by using code numbers rather than personal identifiers and by keeping the questionnaire locked.

\section{Consent for publication}

Not applicable

\section{Competing interests}

The authors declare that they have no competing interests.

\section{Publisher's Note}

Springer Nature remains neutral with regard to jurisdictional claims in published maps and institutional affiliations.

\section{Author details}

${ }^{1}$ Department of Epidemiology and Biostatistics, Institute of Public Health, University of Gondar, Gondar, Ethiopia. ${ }^{2}$ School of Public Health, Faculty of Medicine, the University of Queensland, Sydney, Australia. ${ }^{3}$ Department of Health Informatics, Institute of Public Health, University of Gondar, Gondar, Ethiopia.

Received: 4 September 2017 Accepted: 30 January 2018

Published online: 26 February 2018

\section{References}

1. Nieburg P, NM ML. Role (s) of vaccines and immunization programs in global disease control: mind the Nitty-gritty details: Center for Strategic and. Int Stud. 2012;

2. World Health Organization. WHO vaccine-preventable diseases: monitoring system: 2010 global summary. 2010.

3. Harris JB, Gacic-Dobo M, Eggers R, Brown DW, Sodha SV. Global routine vaccination coverage, 2013. MMWR Morb Mortal Wkly Rep. 2014;63:1055-8.

4. World Health Organization. Challenges in global immunization and the global immunization vision and strategy 2006-2015. Wkly Epidemiol Rec. 2006;81:190e5.

5. Duclos P, Okwo-Bele J-M, Gacic-Dobo M, Cherian T. Global immunization: status, progress, challenges and future. BMC International Health and Human Rights. 2009;9:1.

6. Immunization and Vaccines Development WHO-Africa-World Health Organization. 2015. http://www.afro.who.int/health-topics/immunizationand-vaccines-development. Accessed June 2016. 
7. World Health Organization. Global tuberculosis report 2013: World Health Organization; 2013.

8. Babirye JN, Engebretsen IM, Makumbi F, Fadnes LT, Wamani H, Tylleskar T, et al. Timeliness of childhood vaccinations in Kampala Uganda: a community-based cross-sectional study. PLoS One. 2012;7:e35432.

9. Central statistical agency (CSA) [Ethiopia] and ICF. Ethiopia demographic and health survey. Addis Ababa E, and Rockville, Maryland, USA: CSA and ICF; 2016.

10. CSA I. Ethiopia demographic and health survey. Addis Ababa, Ethiopia and Calverton, Maryland, USA: Central Statistical Agency and ICF International; 2012.

11. Wiysonge CS, Uthman OA, Ndumbe PM, Hussey GD. Individual and contextual factors associated with low childhood immunisation coverage in sub-Saharan Africa: a multilevel analysis. PLoS One. 2012;7:e37905.

12. Unicef. The state of the world's children children in an urban world. eSocialSciences, 2012.

13. UNICEF. Immunization summary: a statistical reference containing data through 2011. 2012.

14. Rahman M, Obaida-Nasrin S. Factors affecting acceptance of complete immunization coverage of children under five years in rural Bangladesh, vol. 52. Salud pública de méxico.; 2010. p. 134-40.

15. Biswas SC, Darda MA, Alam MF. Factors affecting childhood immunisation in Bangladesh. The Pakistan development review. 2001:57-70.

16. Tadesse H, Deribew A, Woldie M. Predictors of defaulting from completion of child immunization in south Ethiopia, may 2008-a case control study. BMC Public Health. 2009;9:1.

17. Maekawa M, Douangmala S, Sakisaka K, Takahashi K, Phathammavong O, Xeuatvongsa $\mathrm{A}$, et al. Factors affecting routine immunization coverage among children aged 12-59 months in Lao PDR after regional polio eradication in western Pacific region. Biosci Trends. 2007;1:43-51.

18. Azhar SS, Nirmal K, Safian N, Rohaizat H, Noor AA, Rozita H. Factors influencing childhood immunization defaulters in sabah, malaysia. The international. Med J Malays. 2012;11(1):17-22.

19. Ibnouf A, Van den Borne H, Maarse J. Factors influencing immunisation coverage among children under five years of age in Khartoum state, vol. 49. Sudan: South African Family Practice; 2007. p. 14

20. Kidane $T$, Tekie $M$. Factors influencing child immunization coverage in a rural district of Ethiopia, 2000. Ethiop J Health Dev. 2003;17:105-10.

21. Jani JV, De Schacht C, Jani IV, Bjune G. Risk factors for incomplete vaccination and missed opportunity for immunization in rural Mozambique. BMC Public Health. 2008:8:1.

22. Shuaib F, Kimbrough D, Roofe M, McGwin Jr G, Jolly P. Factors associated with incomplete childhood immunization among residents of St. Mary parish of Jamaica. The West Indian med J. 2010;59:549.

23. Sanou A, Simboro S, Kouyaté B, Dugas M, Graham J, Bibeau G. Assessment of factors associated with complete immunization coverage in children aged 12-23 months: a cross-sectional study in Nouna district, Burkina Faso. BMC international health and human rights. 2009;9:1

24. Etana B, Deressa W. Factors associated with complete immunization coverage in children aged 12-23 months in ambo Woreda, Central Ethiopia. BMC Public Health. 2012;12:1

25. Maina LC, Karanja S, Kombich J. Immunization coverage and its determinants among children aged 12-23 months in a peri-urban area of Kenya. Pan African Med J. 2013;14:3. https://doi.org/10.11604/pamj.2013.14.3.2181.

26. Naeem M, Khan M, Adil M, Abbas $S$, Khan M, Khan A, et al. Inequity in childhood immunization between urban and rural areas of Peshawar. J Ayub Med Coll Abbottabad. 2011;23:134-7.

27. Nisar N, Mirza M, Qadri MH. Knowledge, attitude and practices of mothers regarding immunization of one year old child at Mawatch Goth, Kemari town, Karachi. Pak J Med Sci. 2010;26:183-6.

28. Bofarraj MA. Knowledge, attitude and practices of mothers regarding immunization of infants and preschool children at al-Beida City, Libya 2008. Egyptian J of Pediatric Allergy and Immunology (The). 2011;9

29. Abdulraheem I, Onajole A, Jimoh A, Oladipo A. Reasons for incomplete vaccination and factors for missed opportunities among rural Nigerian children. J of Public Health and Epidemiology. 2011;3:194-203.

30. Berhane Y, Masresha F, Zerfu M, Kebede S, Shashikant S. Status of expanded program on immunization in a rural town, south Ethiopia. Ethiop Med J. 1995;33:83-93.

31. World Health Organization, Immunization WHODo. Immunization in practice: A practical guide for health staff: World Health Organization; 2015.
32. World Health Organization. Country statistics and global health estimates. Brazil: WHO statistical profile; 2015.

33. World Health Organization. Federal Ministry of Health of Ethiopia. UNICEF: Ethiopian National Expanded program on Immunizatio: Comprehensive Multi-year Plan 2011-2015; 2010.

34. Demographic E. Health Survey: 2005: Central Statistical Agency Addis Ababa, Ethiopia. Maryland: ORC Macro Calverton; 2006.

35. Demographic E. Health Survey 2011, Central Statistical Agency Addis Ababa. Maryland: Ethiopia ICF International Calverton; 2012. p. 70-1.

36. Ethiopia FDRo. Health sector development Programme IV, vol. 11 - 2014/15; 2010.

37. Mohammed $\mathrm{H}$, Atomsa A. Assessment of child immunization coverage and associated factors in Oromia regional state, eastern Ethiopia. Science, technology and arts research. Journal. 2013;2:36-41.

38. Central statistical agency Addis Ababa E. Ethiopia demographic and health survey 2011.

39. Mohamud AN, Feleke A, Worku W, Kifle M, Sharma HR. Immunization coverage of 12-23 months old children and associated factors in Jigjiga District, Somali National Regional State, Ethiopia. BMC Public Health. 2014;14:1.

40. Kassahun MB, Biks GA, Teferra AS. Level of immunization coverage and associated factors among children aged 12-23 months in lay Armachiho District, North Gondar zone, Northwest Ethiopia: a community based cross sectional study. BMC research notes. 2015;8:1.

41. Negussie A, Kassahun W, Assegid S, Factors HAK. Associated with incomplete childhood immunization in Arbegona district, southern Ethiopia: a case-control study. BMC Public Health. 2016;16:1.

\section{Submit your next manuscript to BioMed Central and we will help you at every step:}

- We accept pre-submission inquiries

- Our selector tool helps you to find the most relevant journal

- We provide round the clock customer support

- Convenient online submission

- Thorough peer review

- Inclusion in PubMed and all major indexing services

- Maximum visibility for your research

Submit your manuscript at www.biomedcentral.com/submit
) Biomed Central 